\title{
Correction to: Rising Income Inequality in OECD Countries: Does Fiscal Policy Sacrifce Economic Growth in Achieving Equity?
}

\author{
Chandika Gunasinghe ${ }^{1,2}$ (D) E. A. Selvanathan ${ }^{1} \cdot$ Athula Naranpanawa $^{1}$. \\ John Forster ${ }^{1}$
}

Published online: 9 November 2020

(c) European Association of Development Research and Training Institutes (EADI) 2020

\section{Correction to: The European Journal of Development Research https://doi.org/10.1057/s41287-020-00322-8}

Due to an unfortunate oversight during the correction process the new affiliation of Chandika Gunasinghe has not been included. It should be read: Department of Economics, Faculty of Humanities and Social Sciences, University of Ruhuna, MH 81,000, Matara, Sri Lanka.

Publisher's Note Springer Nature remains neutral with regard to jurisdictional claims in published maps and institutional affiliations.

The original article can be found online at https://doi.org/10.1057/s41287-020-00322-8.

Chandika Gunasinghe gunasinghe@econ.ruh.ac.lk

E. A. Selvanathan e.selvanathan@griffith.edu.au

Athula Naranpanawa a.naranpanawa@griffith.edu.au

John Forster artistjohn.forster@gmail.com

1 Department of Accounting, Finance and Economics, Griffith Business School, Nathan Campus, Griffith University, 170 Kessels Road, Nathan, QLD 4111, Australia

2 Department of Economics, Faculty of Humanities and Social Sciences, University of Ruhuna, Matara 81000, Sri Lanka 